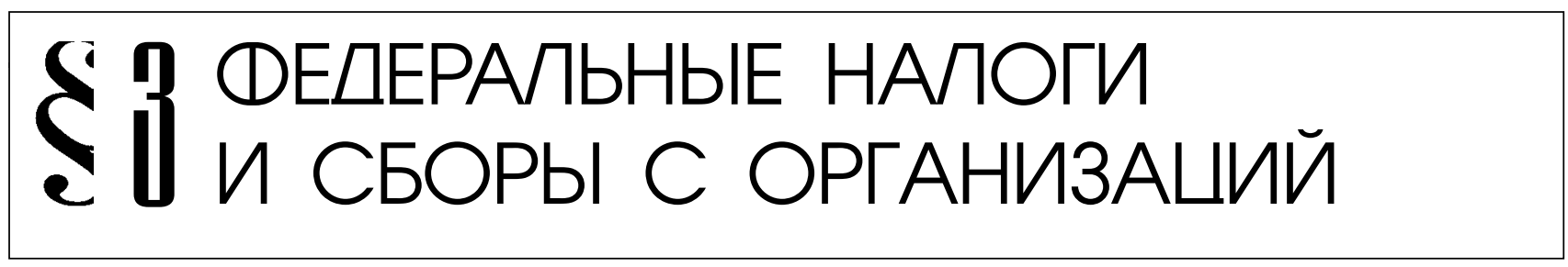

Ф.С. Агузарова

\title{
ПУТИ ПОВЫШЕНИЯ АКЦИЗНЫХ ПОСТУПЛЕНИЙ В БЮДЖЕТЫ БЮДЖЕТНОЙ СИСТЕМЫ РФ
}

\begin{abstract}
Аннотация: Акцизы выступают эффрективным компонентом финансовой и налоговой системы. Для экономики любого государства они являются наиболее надёжным источником доходов бюджета, так как подакцизные товары не влияют на уровень дохода населения, а включаются в стоимость продукции. Целью написания данной статьи является определение факторов, влияющих на повышение роли акцизов в доходах бюджетов бюджетной системы РФ. Проведенный анализ распределения подакцизных товаров раскрыл пропорции их поступления в федеральный бюджет и бюджеты субъектов. Автор статьи доказывает, что наибольший объем подакцизных товаров зачисляется в федеральный бюджет. Поступления по акцизам за анализируемый период имеют тенденцию к повышению. Выявить факторы повышения акцизов в доходах бюджета стало возможным в ходе применения исследовательского и поискового методов, а также сравнительного и графического методов. В заключении определены проблемы акцизного налогообложения. Наиболее остро стоит проблема в деятельности алкогольного производства - нелегальный сбыт спиртосодержащей и алкогольной продукции. В целях совершенствования акцизной продукции целесообразно вводить меры по ужесточению контрольной деятельности налоговых служб так, чтобы легализовать всю подакцизную продукцию, вводить жесткие меры наказания.
\end{abstract}

Ключевые слова: акцизы, косвенные налоги, подакцизные товары, налоговое регулирование, доход, спиртосодержащая продукция, алкогольная продукция, табачная продукция, бюджет, экономика.

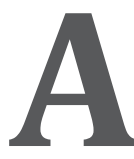

кцизы относятся к косвенным федеральным налогам, взимаемым с налогоплательщиков, производящих и реализующих подакцизную продукцию. Они увеличивают цену товара и оплачиваются конечным потребителем, взимаются в основном в сфере производства, в то время как второй косвенный налог - НДС, взимается не только в производственной сфере, но и в сфере обращения. Акцизами облагается ограниченный перечень товаров, называемый подакцизными товарами. Согласно налоговому законодательству в состав подакцизных товаров входит: этиловый спирт; сигареты, сигариллы, папиросы и другая табачная продукция; легковые автомобили; топливо печное бытовое, вырабатываемое из дизельных фракций прямой перегонки и вторичного происхождения, кипящих в интервале температур от 280 до 3600С; мотоциклы (свыше 150 л.с.); бензин и дизельное топливо; моторные масла. ${ }^{1}$

\footnotetext{
1 Налоговый кодекс Российской Федерации. - М.: Элит, 2014.
} 
Как эффективный компонент финансовой и налоговой системы акцизы являются важнейшей статьей доходной части бюджета и наиболее результативным механизмом государственного регулирования алкогольного и табачного рынка, а также автоиндустрии. Они уплачиваются однократно производителем подакцизного товара или его импортером. При последующей перепродаже товара, в отношении которого акциз уже был уплачен, повторное его взимание не производится. Хотя имеет место быть обратная ситуация.

Очевидно, что подакцизные товары имеют всеобщую черту: спрос на эти товары не влияет на уровень дохода населения. Преимуществом акцизов является его стабильное изъятие при любой экономической ситуации в стране.

На сегодняшний день обложение акцизами имеет ряд преимуществ. Во-первых, они отличаются быстрым поступлением в бюджет, так как при реализации товаров непременно проводится перечисление налога в бюджет, то есть произошла реализация, сразу взимается сумма налога. Во-вторых, поскольку акцизы охватывают товары массового потребления, пользующихся наибольшим спросом, имеется значительный объем поступлений в бюджетный фонд государства. В-третьих, акцизы выполняют экономическую функцию во всех субъектах федерации при распределении акцизных доходов. В-четвертых, акцизы существенно влияют на финансовую обеспеченность самого государства, поскольку, чем больше выпуск продукции и его сбыт, тем значительнее доля поступления. При разумном их использовании государство может регулировать процесс потребления, изменяя размер налога с помощью ставок, тем самым, меняя его цену и делая товар более доступным для потребителя.
Вместе с тем акцизные платежи до сих пор не совершенствованы и не отвечают требованиям своей экономической природы происхождения, а также социальному назначению, что подчеркивает актуальность данной проблематики.

Экономическое развитие государства может иметь циклический характер, чередуясь экономическим ростом и спадами. ${ }^{2}$ Так вот в момент спада экономики, когда уменьшаются макроэкономические показатели, происходит уменьшение базы налогообложения, а это приводит к сокращению доли доходов бюджета. Не секрет, что база прямых налогов является более неустойчивой к экономическим колебаниям, чем база косвенных налогов. В период экономических катаклизм акцизы выступают наиболее надежным источником доходов бюджетов. Это связано с тем, что косвенные налоги входят в стоимость товара, спрос на которые сохраняется при любых условиях экономики. Тогда как, прямые налоги уплачиваются с дохода, которого может не быть в этот период у налогоплательщика или с имущества, на уплату которого просто не будет представлена возможность граждан или организаций по причине отсутствия денежных средств.

Очевидно, что составляющая акцизных поступленийв бюджетах наиболее высока при максимальном объеме выпуска производимых подакцизных товаров и высоких ставках на эти товары. Исследования аналитиков и экспертов показывают, что введение акцизов или повышение ставок уже введённых акцизов способствует росту общего уровня цен в стране. Следовательно, любые изменения по акцизам разумней

\footnotetext{
2 Агузарова Л.А. Методы государственного регулирования процессов воспроизводства социально-трудового потенциала в депрессивных регионах СКФО//Региональная экономика: теория и практика. №8. 2013. с. 23-28.
} 
Распределение подакцизных товаров между бюджетами бюджетной системы РФ на 01.01.2014 год (\%)

\begin{tabular}{|l|c|c|}
\hline \multicolumn{1}{|c|}{ Название показателя } & $\begin{array}{c}\text { Федеральный } \\
\text { бюджет }\end{array}$ & $\begin{array}{c}\text { Бюджеты } \\
\text { субъектов }\end{array}$ \\
\hline акцизов на спирт этиловый из пищевого сырья & 50 & 50 \\
\hline $\begin{array}{l}\text { акцизов на спирт этиловый из всех видов сырья, за исключе- } \\
\text { нием пищевого }\end{array}$ & 100 & 0 \\
\hline акцизов на спиртосодержащую продукцию & 50 & 50 \\
\hline $\begin{array}{l}\text { акцизов на алк. продукцию с объемной долей этил. спирта, } \\
\text { более 9 \%, за искл. пива, вин, фруктовых вин, игристых вин } \\
\text { (шампанских), винных напитков, изготавл. без добавления } \\
\text { ректификованного этил. спирта, произведенного из пищево- } \\
\text { го сырья, и спиртованных виноградного или иного фрукто- } \\
\text { вого сусла, и винного дистиллята, и фруктового дистиллята }\end{array}$ & 60 & \\
\hline акцизов на табачную продукцию & & \\
\hline $\begin{array}{l}\text { акцизов на автомобильный и прямогонный бензин, дт, мо- } \\
\text { торные масла для диз. и карб. двигателей, производимые на } \\
\text { территории России }\end{array}$ & 28 & 72 \\
\hline акцизов на автомобили легковые и мотоциклы & \\
\hline $\begin{array}{l}\text { акцизов по подакцизным товарам и продукции, ввозимым на } \\
\text { территорию России }\end{array}$ & 100 & \\
\hline $\begin{array}{l}\text { акцизов на алк. продукцию с объемной долей этил.спиртабо- } \\
\text { лее 9\%, включ. пиво, вина, фруктовые вина, игристые вина } \\
\text { (шампанские), винн. напитки, изготавл. без добавления рек- } \\
\text { тификованного этил. спирта, произв. из пищевого сырья, и } \\
\text { спиртованных виноградного или иного фруктового сусла, и } \\
\text { винного дистиллята, и фруктового дистиллята }\end{array}$ & & \\
\hline $\begin{array}{l}\text { акцизов на алкогольную продукцию с объемной долей этил. } \\
\text { спирта до 9\% включительно }\end{array}$ & 0 & 0 \\
\hline
\end{tabular}

Источник: Бюджетный кодекс РФ. - М.: Элит., 2014. ст. ст. 50, 56.

всего вводить в период стабильного состояния экономики. ${ }^{3}$

Порождает экономические споры среди ученых и практиков механизм распределения акцизов между бюджетами. Основная часть акцизов поступает в федеральный бюджет. Их доля в общей сумме

\footnotetext{
3 Тегетаева О.Р. Роль акцизного налогообложения в регулировании экономических процессов// TerraEconomicus. 2012. T. 10. № 2-2. C. 60-64.
}

налоговых доходах федерального бюджета весьма ощутима.

Рассмотрим нормативы распределения акцизов между бюджетами бюджетной системы РФ на 01.01.2014 год. (Таблица 1).

Данные таблицы 1 показывают, что в 2014 году полностью в федеральный бюджет поступают: акцизы на спирт этиловый из всех видов сырья, за исключением пищевого; акцизы на табачную продукцию; акцизы на автомобили легковые и мото- 
циклы; акцизы по подакцизным товарам и продукции, ввозимым на территорию РФ. Поровну между федеральным бюджетом и субъектами распределяются акцизы на спирт этиловый из пищевого сырья и акцизы на спиртосодержащую продукцию (по 50\%). Всецело в бюджеты субъектов РФ зачисляются: акцизы на алкогольную продукцию с объемной долей этилового спирта до 9\% включительно и более 9\%, включающих пиво, вина, фруктовые вина, игристые вина (шампанские), винные напитки, изготавливаемые без добавления ректификованного этилового спирта, произв. из пищевого сырья, и спиртованных виноградного или иного фруктового сусла, и винного дистиллята, и фруктового дистиллята. 60\% акциз поступают в федеральный бюджет на алкогольную продукцию с объемной долей этилового спирта более 9 \%, за исключением пива, вин, фруктовых вин, игристых вин (шампанских), винных напитков, изготавливаемых без добавления ректификованного этилового спирта, произведенного из пищевого сырья, и спиртованных виноградного или иного фруктового сусла, и винного дистиллята, и фруктового дистиллята. Следовательно, другие 40\% поступают в бюджеты субъектов РФ. Акцизы на автомобильный и прямогонный бензин, дизельное топливо, моторные масла двигателей, производимые на территории РФ, распределяются в следующих пропорциях: 28\% - в федеральный бюджет и 72\% - в региональные бюджеты.

Проведем анализ роли акцизов в бюджетах бюджетной системы РФ за 20102012 гг. (Таблица 2).

По данным таблицы 2 видно, что в 2010 году общий объем налоговых доходов составил 4401,9 млрд. руб. Акцизы состоят в группах: «Налоги на товары, реализуемые на территории РФ»; «Налоги на товары, ввозимые на территорию РФ». В их числе налоги на товары, реализуемые на территории РФ, собраны в размере 1442,6 млрд. руб., из них акцизы исполнены в сумме 113,9 млрд. руб. Значительны поступления по налогам на товары, ввозимым на территорию РФ. Показатели исполнения по ним составили - 1199,6 млрд. руб., из которых лишь 30,1 млрд. руб. составляющая по акцизам.

В 2011 году налоговые доходы собраны в размере 5985,3 млрд. руб. Из них показатели исполнения налогов на товары, реализуемые на территории РФ равны 1985,1 млрд. руб., из которых акцизы - 231,9 млрд. руб. Увеличились показатели исполнения по налогам на товары, ввозимые на территорию РФ до 1543,8 млрд. руб., из них акцизы - 46,6 млрд. руб.

В 2012 году налоговые доходы выросли до 6846,4 млрд. руб. Слагаемая налога на добавленную стоимость - 1881,3 млрд. руб. и акцизов - 341,7 млрд. руб., составила показатель исполнения налогов на товары, реализуемых на территории РФ 2223,0 млрд. руб. Показатели исполнения по группе «Налоги на товары, ввозимые на территорию РФ» составили 1712,6 млрд. руб., в том числе акцизы - 53,4 млрд. руб.

Что касается республиканского бюджета РСО-Алания, то здесь следует отметить следующее. Согласно бюджетному законодательству РФ в бюджеты субъектов федерации из числа косвенных налогов поступают только налоги на товары, реализуемые на территории РФ, в состав которых входят только акцизы (НДС в бюджеты субъектов не поступает). Не поступают в региональные бюджеты налоги на товары, ввозимые на территорию РФ.

В 2010 году налоговые доходы бюджета республики исполнены в объеме 


\section{Удельный вес акцизов в налоговых доходах бюджетов} бюджетной системы РФза 2010-2012 гг.

\begin{tabular}{|c|c|c|c|c|c|c|}
\hline \multirow[b]{2}{*}{$\begin{array}{c}\text { Наименование } \\
\text { дохода }\end{array}$} & \multicolumn{2}{|c|}{2010 г. } & \multicolumn{2}{|c|}{2011 r. } & \multicolumn{2}{|c|}{2012 г. } \\
\hline & $\begin{array}{c}\text { Факт, } \\
\text { млрд. } \\
\text { руб. }\end{array}$ & $\begin{array}{c}\text { Уд.вес, } \\
\%\end{array}$ & $\begin{array}{c}\text { Факт, } \\
\text { млрд. } \\
\text { руб. }\end{array}$ & $\begin{array}{c}\text { Уд.вес, } \\
\%\end{array}$ & $\begin{array}{c}\text { Факт, } \\
\text { млрд. } \\
\text { руб. }\end{array}$ & $\begin{array}{c}\text { Уд.вес, } \\
\%\end{array}$ \\
\hline \multicolumn{7}{|l|}{ Федеральный бюджет ${ }^{*}$} \\
\hline $\begin{array}{l}\text { Налоговые доходы } \\
\text { в их числе: }\end{array}$ & 4401,9 & 100,0 & 5985,2 & 100,0 & 6853,1 & 100,0 \\
\hline $\begin{array}{l}\text { Налоги на товары, реа- } \\
\text { лизуемые на территории } \\
\text { Российской Федерации } \\
\text { из них: }\end{array}$ & 1442,6 & 32,8 & 1985,1 & 33,2 & 2223,0 & 32,5 \\
\hline $\begin{array}{l}\text { Налог на добавленную } \\
\text { стоимость }\end{array}$ & 1328,7 & 30,2 & 1753,2 & 29,3 & 1881,3 & 27,5 \\
\hline Акцизы & 113,9 & 2,6 & 231,9 & 3,9 & 341,7 & 4,9 \\
\hline $\begin{array}{l}\text { Налоги на товары, ввози- } \\
\text { мые на территорию РФ } \\
\text { из них: }\end{array}$ & 1199,6 & 27,3 & 1543,8 & 25,8 & 1712,6 & 25,0 \\
\hline $\begin{array}{l}\text { Налог на добавленную } \\
\text { стоимость }\end{array}$ & 1169,5 & 26,6 & 1497,2 & 25,0 & 1659,3 & 24,2 \\
\hline Акцизы & 30,1 & 0,7 & 46,6 & 0,8 & 53,4 & 0,8 \\
\hline \multicolumn{7}{|c|}{ Республиканский бюджет РСО-Алания** } \\
\hline $\begin{array}{l}\text { Налоговые доходы } \\
\text { в их числе: }\end{array}$ & 6,7 & 100,0 & 7,5 & 100,0 & 8,7 & 100,0 \\
\hline Акцизы & 1,5 & 22,4 & 1,5 & 20,0 & 1,4 & 16,1 \\
\hline
\end{tabular}

* roskazna.ru.

** Отчетные данные законов РСО-Алания «Об исполнении республиканского бюджета РСО-Алания за 2010-2012 гг.».

6,7 млрд. руб., из которых 1,5 млрд.руб. составили акцизы. В 2011 году налоговые доходы увеличились и составили 7,5 млрд. руб., где 1,5 млрд. руб. - акцизы. На 2 млрд. руб. с 2010 года увеличились налоговые доходы в 2012 году и составили 8,7 млрд. руб. В числе налоговых поступлений акцизы заняли 1,4 млрд. руб.

Таким образом, проведенный анализ показал, что в федеральном бюджете за 2010-2012 гг. наибольший объем поступлений по акцизам наблюдается в группе «Налоги на товары, реализуемые на тер- ритории РФ». В 2010 году из 32,8\% акцизам принадлежит 2,6\%; в 2011 году из $33,2 \% 3,9 \%$ - доля акцизов \%; в 2012 году из 32,5\% акцизы заняли 4,9\%. Объем поступлений налогов на товары, ввозимых на территорию РФ за 2010-2012 гг. меньше и составил: $27,3 \% ; 25,8 \% ; 25,0 \%$ соответственно. В их числе акцизы составили: 0,7\%; 0,7\%; 0,8\% соответственно. Если доходы по акцизам в федеральном бюджете растут, а также увеличивается удельный вес в общей сумме налоговых доходов, то в бюджете субъекта РСО-Алания они пада- 
DOI: $10.7256 / 1812-8688.2014 .3 .11532$

При цитировании этой статьи сноска на doi обязательна

Федеральные налоги и сборы с организаций

\section{Динамика поступления акцизов в бюджетах бюджетной системы РФ за 2010-2012 гг. (млрд. руб.)}

\begin{tabular}{|c|c|c|c|c|c|}
\hline \multirow{2}{*}{ Наименование показателя } & \multirow{2}{*}{2010 г. } & \multirow{2}{*}{2011 г. } & \multirow{2}{*}{2012 г. } & \multicolumn{2}{|c|}{$\begin{array}{c}\text { Темп роста, } \\
+; \text { - }\end{array}$} \\
\hline & & & & $\begin{array}{l}2011 \text { г. } \\
\text { К } 2010 \text { г. }\end{array}$ & $\begin{array}{c}2012 \text { г. } \\
\text { к } 2011 \text { г. }\end{array}$ \\
\hline \multicolumn{6}{|l|}{ Федеральный бюджет ${ }^{3}$} \\
\hline $\begin{array}{l}\text { Налоговые доходы } \\
\text { в том числе: }\end{array}$ & 4401,9 & 5985,3 & 6846,4 & $+1583,4$ & $+861,1$ \\
\hline $\begin{array}{l}\text { Налоги на товары, реализуемы } \\
\text { на территории РФ }\end{array}$ & & & & & \\
\hline из них: & 1442,6 & 1985,1 & 2223,0 & $+542,5$ & $+237,9$ \\
\hline Акцизы & 113,9 & 231,9 & 341,7 & +118 & $+109,8$ \\
\hline $\begin{array}{l}\text { Налоги на товары, ввозимые на } \\
\text { территорию РФ } \\
\text { из них: }\end{array}$ & 1199,6 & 1543,8 & 1712,6 & $+344,2$ & $+168,8$ \\
\hline Акцизы & 30,1 & 46,6 & 53,4 & $+16,5$ & $+6,8$ \\
\hline \multicolumn{6}{|c|}{ Республиканский бюджет РСО-Алания ${ }^{4}$} \\
\hline $\begin{array}{l}\text { Налоговые доходы } \\
\text { в их числе: }\end{array}$ & 6,7 & 7,5 & 8,7 & $+0,8$ & $+1,2$ \\
\hline Акцизы & 1,5 & 1,5 & 1,4 & 0,0 & $-0,1$ \\
\hline
\end{tabular}

* roskazna.ru.

** Отчетные данные законов РСО-Алания «Об исполнении республиканского бюджета РСО-Алания за 2010-2012 гг.».

ют. Удельный вес акцизов в сумме налоговых доходов республики составил: в 2010 году - 22,4\%; в 2011 году - 20,0\%; в 2012 году $-16,1 \%$.

Покажем прирост акцизов в бюджетах бюджетной системы РФ за 2010-2012 гг. (Таблица 3).

По данным таблицы 3 видно, что за 2010-2012 гг. налоговые доходы, как федерального бюджета, так и бюджета РСОАлания, растут. В числе налоговых доходов федерального бюджета увеличиваются налоги на товары, реализуемые на территории РФ и ввозимые на территорию РФ, в состав которых входят акцизы. Так, акцизы, реализуемые на территории РФ, увеличились в 2011 году на 118,0 млрд. руб., а в 2012 году еще на 109,8 млрд. руб. Акцизы, ввозимые на территорию РФ, также увеличились в 2011 году на 16,5 млрд. руб., а в 2012 году на 6,8 млрд. руб. Повышающая тенденция акцизов, в первую очередь, обусловлена индексацией ставок по подакцизным товарам.

В целом налоговые доходы республиканского бюджета РСО-Алания имеют повышающую динамику, что нельзя сказать об акцизах. Показатели исполнения акцизов в 2011 году не изменились и составили как в предыдущем году 1,5 млрд. руб., а в 2012 году сократились до 1,4 млрд. руб., что меньше на 0,1 млрд. руб.

\footnotetext{
4 Агузарова Л.А. Налоговый потенциал региона и повышение эффективности планирования налоговых доходов (на материалах РСО-Алания)//Налоги и налогообложение. №11. 2013. с. 818-824.
} 
DOI: $10.7256 / 1812-8688.2014 .3 .11532$

При цитировании этой статьи сноска на doi обязательна

Налоги и налогообложение - №3(117)• 2014

Таким образом, за 2010-2012 гг. показатели исполненияналоговых доходовв бюджетах бюджетной системы возрастают. В их числе акцизы занимают приоритетную позицию.

Проведенный анализ позволил выявить проблемы администрирования акцизов. Следует рассмотреть актуальные проблемы акцизного налогообложения и предложить возможные пути их решения.

Процесс активного законотворчества в сфере акцизного налогообложения, развивающийся в РФ в течение последних нескольких лет, вызывает необходимость комплексного научного анализа.

Проблема акцизного налогообложения является весьма острой темой реформирования законодательства, так как акцизы играют существенную роль в экономической системе.

Важно отметить, что наиболее часто проблемы по акцизам встречаются в деятельности алкогольного производства. Производители алкогольной продукции обходят государственные интересы и преследуют исключительно только собственные цели. ${ }^{5}$ А именно, реализуют алкогольную продукцию за цену, установленную ниже рыночной, при этом учитывая только свои собственные цели и не учитывая интересы государства. Сегодня уполномоченный государственный орган Росалкогольрегулирование установил минимальную розничную цену на полулитровую бутылку водки. Относительно 2013 года она увеличилась на $17 \%$ и стоит до 199 руб. Известно, что на «черном» рынке такую бутылку можно приобрести за стоимость

\footnotetext{
5 Токаева С.К. К вопросу о повышении акцизов// Международная научно-практическая конференция «Поиск модели эффективного развития: экономикоправовые аспекты реализации стратегии модернизации России» о. Кипр, 2-9 ноября 2013 г.
}

гораздо меньше установленной, что значит нелегальный сбыт. Розничная продажа алкогольной продукции должна осуществляться исключительно по ценам не ниже установленных уполномоченным органом государственной власти.

Продажа подакцизной продукции на «черном» рынке порождает немало проблем. Во-первых, именно в данном случае производители через посредников реализуют свою безакцизную продукцию, не уплатив налоги. Во-вторых, этот товар не качественный и опасный для жизни людей.

В данном случае проблему нужно решать административно. Нужно принимать меры по ужесточению контрольной деятельности налоговых служб в сфере акцизного налогообложения. С помощью грамотной и эффективной деятельности контролируемых органов можно выявлять незаконопослушных производителей, штрафовать их большими размерами денежных сумм, тестировать спиртосодержащую продукцию, запрещать на определенный период времени производство и сбыт подакцизной продукции, а при не соблюдении и выполнении установленного наказания аннулировать лицензию организации по выпуску подакцизной продукции, либо повысить размер уставного капитала организаций. ${ }^{6}$

В ходе формирования налоговой политики государства совершенствовать акцизы разумно следующим образом. Дифференцировать ставки акциза на этиловый спирт и предусмотреть вероятность освобождения от авансовой уплаты акциза по покупаемому спирту в случае представления производителями банковской гаран-

\footnotetext{
6 Токаев Н.Х. Самостоятельность и автономия экономического развития местных территориальных образований/Стратегия устойчивого развития регионов России. - 2013. - № 17. С 230-234.
} 
DOI: $10.7256 / 1812-8688.2014 .3 .11532$

При цитировании этой статьи сноска на doi обязательна

Федеральные налоги и сборы с организаций

тии. ${ }^{7}$ Предоставление банковской гарантии претерпело некоторые изменения с 2014 года. Согласно налоговому законодательству перевозки этилового спирта подлежат лицензированию. При этом транспортирование должно разрешаться лишь транспортом, оборудованным специальными техническими средствами, которые могут в автоматическом режиме фиксировать движения автомобиля. Все данные о местонахождении таких транспортных средств должны передаваться в единую автоматизированную систему контроля перевозок. Указанная процедура даст возможность отследить полную и своевременную доставку продукции, а также легальный сбыт. ${ }^{8}$

Органами ФНС РФ были выявлены правонарушения в отношении производства алкогольной продукции. Зачастую производители используют выгодную для них подакцизную продукцию в своей деятельности, ставки которых ниже. ${ }^{9}$ Например, в 2014 году ставки спиртосодержащей продукции составили 400 руб. за 1 литр. Ставки алкогольной продукции несколько выше и составили 500 руб. за 1 литр. Организации и индивидуальные предприниматели преследуя свои цели, изготавливают алкогольную продукцию на основе спиртосодержащей продукции с целью экономии на налогах. Это приводит к сокращению суммы акцизов, выпадению доходов из бюджета и частичному уклонению от уплаты налогов.

В практической деятельности некоторые трудности возникают при импор-

\footnotetext{
7 Тегетаева О.Р. Эффективность применения ставок акцизов в механизме акцизного налогообложения// Управление экономическими системами, 2012. № 3 (39).

8 Основные направления налоговой политики РФ на 2014 год и на плановый период 2015 и 2016 годов//СПС Консультант плюс.

9 http://ria.ru/economy.www.gks.ru.
}

тировании подакцизной продукции, в частности идентификации вин. Так как в налоговом законодательстве не имеются разъяснения для целей налогообложения того, какая алкогольная продукция является натуральной, наличествуют некоторые недоработки таможенного контроля по достоверности заявляемых при таможенном оформлении сведений по уплате акцизов. ${ }^{10}$ В нынешней практике отсутствуют единые параметры отнесения вин к категории натуральных, что дает возможность заявлять неточные сведения о товаре с целью занижения платежей. В следствии большинство вин, ввозимых в РФ, декларируются как натуральные и облагаются акцизом по сниженной ставке. Данное обстоятельство приводит к потерям денежных средств бюджетного фонда страны. Целесообразно развивать виноделие внутри страны. На территории РФ возделывание виноградников возможно на Северном Кавказе, в частности, в Дагестане, Краснодарском крае. Необходимо с помощью новейших технологий выращивать разные сорта винограда на указанных территориях РФ с целью укрепления налоговой составляющей бюджетов.

Несовершенство акцизов подтверждается внесением ежегодных многочисленных поправок в законодательство. Например, с 01.01.2014 года помимо установленной индексации, предусмотрена дополнительная индексация по ставкам акцизов на автомобильный бензин классов 4 и 5. Так, в 2014 году на бензин 4-го класса

\footnotetext{
10 Экономические основы налоговых отношений// сборник научных трудов/М-во образования и науки Российской Федерации, Федеральное гос. бюджетное образовательное учреждение высш. проф. образования «Сев. - Осетинский гос. ун-т им. К. Л. Хетагурова» ; [редкол.: Агузарова Л. А. (отв. ред.) и др.]. Владикавказ, 2011.
} 
ставка равна 9916 руб. (вместо 9416 руб.) за 1 т., в 2015 г. - 10858 руб. (10358 руб.) за $1 \mathrm{~T}$, а на бензин 5-го класса: в 2014 г. -6450 руб. (5750 руб.) за 1 т., в 2015 г. - 7750 руб. (6223 руб.) за 1 т.

Бытует мнение о замене регионального транспортного налога акцизами на горюче-смазочные материалы. На наш взгляд, при отказе от транспортного налога существенно увеличатся ставки на реализацию горюче смазочных материалов. Кроме того, следует учесть деятельность отдельных организаций, заводов, которые в своей работе используют ГСМ, но не используют транспортные средства. Акцизы уплачиваются нефтеперерабатывающими предприятиями, а транспортный налог - отдельными физическими и юридическими лицами. Прежде чем трансформироватьналоги нужно выработать правильный алгоритм, учитывающий все стороны вопроса. ${ }^{11}$

Таким образом, в целях совершенствования акцизной продукции целесообразно вводить меры по ужесточению контрольной деятельности налоговых служб, так чтобы легализовать всю подакцизную продукцию, в противном случае, применять жесткие меры наказания. Кроме того, необходимо внедрять долгосрочную государственную программу по возрождению виноградарства и виноделия в РФ. И самое главное, создать стабильное и однозначное налоговое законодательство в области акцизного налогообложения.

\section{Библиография:}

1. Налоговый кодекс Российской Федерации. - М.: Элит, 2014.

2. Бюджетный кодекс РФ. - М.: Элит, 2014.

3. Основные направления налоговой политики РФ на 2014 год и на плановый период 2015 и 2016 годов//СПС Консультант плюс.

4. Отчетные данные законов РСО-Алания «Об исполнении республиканского бюджета РСО-Алания за 2010-2012 гг.».

5. Агузарова Л.А. Методы государственного регулирования процессов воспроизводства социально-трудового потенциала в депрессивных регионах СКФО//Региональная экономика: теория и практика. №8. 2013. с. 23-28.

6. Агузарова Л.А. Налоговый потенциал региона и повышение эффективности планирования налоговых доходов (на материалах РСО-Алания)//Налоги и налогообложение. №11. 2013. с. 818-824.

7. Дзагоева М.Р. Институциональные основы региональной налоговой политики: учеб. пособие: для студентов, обучающихся по специальности «Финансы и кредит»/М. Р. Дзагоева; М-во образования Рос. Федерации, Сев. — Осет. гос. ун-т им. К. Л. Хетагурова. Владикавказ, 2004.

8. Тихонова С.С. Об основных направлениях налоговой политики РФ на 2014 год и на плановый период 2015 и 2016 гг.//Бухучет в здравоохранении. — 2013. — № 10. С. 6-12.

11 Дзагоева М.Р. Институциональные основы региональной налоговой политики: учеб.пособие: для студентов, обучающихся по специальности «Финансы и кредит»/ М. Р. Дзагоева; М-во образования Рос. Федерации, Сев. Осет. гос. ун-т им. К. Л. Хетагурова. Владикавказ, 2004. 
9. Тегетаева О.Р. Роль акцизного налогообложения в регулировании экономических процессов//TerraEconomicus. 2012. Т. 10. № 2-2. С. 60-64.

10. Тегетаева О.Р. Эффективность применения ставок акцизов в механизме акцизного налогообложения//Управление экономическими системами, 2012. № 3 (39).

11. Токаев Н.Х. Самостоятельность и автономия экономического развития местных территориальных образований/Стратегия устойчивого развития регионов России. 2013. — № 17. C 230-234.

12. Токаева С.К. К вопросу о повышении акцизов//Международная научно-практическая конференция «Поиск модели эффективного развития: экономико-правовые аспекты реализации стратегии модернизации России» о. Кипр, 2-9 ноября 2013 г.

13. Троянская М.А., Низамиева Ю.О. Совершенствование акцизного налогообложения как инструмента налогового регулирования//Российское предпринимательство. 2013. — № 14 (236). С. 157-163.

14. Экономические основы налоговых отношений//сборник научных трудов/М-во образования и науки Российской Федерации, Федеральное гос. бюджетное образовательное учреждение высш. проф. образования «Сев. - Осетинский гос. ун-т им. К. Л. Хетагурова» ; [редкол.: Агузарова Л. А. (отв. ред.) и др.]. Владикавказ, 2011.

15. http://ria.ru/economy.www.gks.ru.

16. roskazna.ru.

17. Э.Д. Соколова Правовое регулирование бюджетной деятельности государства и муниципальных образований (теория и правотворчество) // Финансовое право и управление. - 2013. - 2. - С. 119 - 135. DOI: 10.7256/2310-0508.2013.2.9868.

18. Кучерявенко Н.П. Согласование родовых и видовых конструкций при регулировании бюджетных доходов // Финансовое право и управление. - 2014. - 1. - С. 120-140. DOI: $10.7256 / 2310-0508.2014 .1 .9886$.

\section{References:}

1. Nalogovyi kodeks Rossiiskoi Federatsii. — M.: Elit, 2014.

2. Byudzhetnyi kodeks RF. - M.: Elit, 2014.

3. Osnovnye napravleniya nalogovoi politiki RF na 2014 god i na planovyi period 2015 i 2016 godov//SPS Konsul'tant plyus.

4. Otchetnye dannye zakonov RSO-Alaniya «Ob ispolnenii respublikanskogo byudzheta RSOAlaniya za 2010-2012 gg.».

5. Aguzarova L.A. Metody gosudarstvennogo regulirovaniya protsessov vosproizvodstva sotsial'no-trudovogo potentsiala $\mathrm{v}$ depressivnykh regionakh SKFO//Regional'naya ekonomika: teoriya i praktika. №8. 2013. s. 23-28.

6. Aguzarova L.A. Nalogovyi potentsial regiona i povyshenie effektivnosti planirovaniya nalogovykh dokhodov (na materialakh RSO-Alaniya)//Nalogi i nalogooblozhenie. №11. 2013. s. 818-824.

7. Dzagoeva M.R. Institutsional'nye osnovy regional'noi nalogovoi politiki: ucheb. posobie: dlya studentov, obuchayushchikhsya po spetsial'nosti «Finansy i kredit»/M. R. Dzagoeva; M-vo obrazovaniya Ros. Federatsii, Sev. — Oset. gos. un-t im. K. L. Khetagurova. Vladikavkaz, 2004. 
8. Tikhonova S.S. Ob osnovnykh napravleniyakh nalogovoi politiki RF na 2014 god i na planovyi period 2015 i 2016 gg.//Bukhuchet v zdravookhranenii. — 2013. — № 10. S. 6-12.

9. Tegetaeva O.R. Rol' aktsiznogo nalogooblozheniya $\mathrm{v}$ regulirovanii ekonomicheskikh protsessov//TerraEconomicus. 2012. T. 10. № 2-2. S. 60-64.

10. Tegetaeva O.R. Effektivnost' primeneniya stavok aktsizov $\mathrm{v}$ mekhanizme aktsiznogo nalogooblozheniya//Upravlenie ekonomicheskimi sistemami, 2012. № 3 (39).

11. Tokaev N.Kh. Samostoyatel'nost' i avtonomiya ekonomicheskogo razvitiya mestnykh territorial'nykh obrazovanii/Strategiya ustoichivogo razvitiya regionov Rossii. -2013 . № 17. S 230-234.

12. Tokaeva S.K. K voprosu o povyshenii aktsizov//Mezhdunarodnaya nauchno-prakticheskaya konferentsiya «Poisk modeli effektivnogo razvitiya: ekonomiko-pravovye aspekty realizatsii strategii modernizatsii Rossii» o. Kipr, 2-9 noyabrya $2013 \mathrm{~g}$.

13. Troyanskaya M.A., Nizamieva Yu.O. Sovershenstvovanie aktsiznogo nalogooblozheniya kak instrumenta nalogovogo regulirovaniya//Rossiiskoe predprinimatel’stvo. — 2013. — № 14 (236). S. 157-163.

14. Ekonomicheskie osnovy nalogovykh otnoshenii//sbornik nauchnykh trudov/M-vo obrazovaniya i nauki Rossiiskoi Federatsii, Federal'noe gos. byudzhetnoe obrazovatel'noe uchrezhdenie vyssh. prof. obrazovaniya «Sev. — Osetinskii gos. un-t im. K. L. Khetagurova» ; [redkol.: Aguzarova L. A. (otv. red.) i dr.]. Vladikavkaz, 2011.

15. http://ria.ru/economy.www.gks.ru.

16. roskazna.ru.

17. E.D.Sokolova Pravovoeregulirovaniebyudzhetnoideyatel'nostigosudarstvaimunitsipal'nykh obrazovanii (teoriya i pravotvorchestvo) // Finansovoe pravo i upravlenie. - 2013. - 2. C. 119 - 135. DOI: 10.7256/2310-0508.2013.2.9868.

18. Kucheryavenko N.P. Soglasovanie rodovykh i vidovykh konstruktsii pri regulirovanii byudzhetnykh dokhodov // Finansovoe pravo i upravlenie. - 2014. - 1. - C. 120-140. DOI: $10.7256 / 2310-0508.2014 .1 .9886$. 